\title{
A collaborative care skills workshop for carers: can it be delivered in 1 day?
}

Article

Accepted Version

Jenkins, P. E., Bues, S., Cottrell, J., Hawkins, J., Pinder, L., Price, S. and Stewart, A. (2018) A collaborative care skills workshop for carers: can it be delivered in 1 day? Clinical Psychology \& Psychotherapy, 25 (1). pp. 130-137. ISSN 10633995 doi: https://doi.org/10.1002/cpp.2119 Available at https://centaur.reading.ac.uk/76086/

It is advisable to refer to the publisher's version if you intend to cite from the work. See Guidance on citing.

To link to this article DOI: http://dx.doi.org/10.1002/cpp.2119

Publisher: Wiley

All outputs in CentAUR are protected by Intellectual Property Rights law, including copyright law. Copyright and IPR is retained by the creators or other copyright holders. Terms and conditions for use of this material are defined in the End User Agreement.

\section{www.reading.ac.uk/centaur}

\section{CentAUR}

Central Archive at the University of Reading 
Reading's research outputs online 
A collaborative care skills workshop for carers: can it be delivered in one day?

Paul E. Jenkins ${ }^{1,2}$, Sonia Bues ${ }^{1}$, Julie Cottrell ${ }^{1}$, Joel Hawkins ${ }^{1}$, Laura Pinder ${ }^{1}$, Susan Price ${ }^{1}$, Anne Stewart ${ }^{1}$

${ }^{1}$ Oxford Health NHS Foundation Trust, Warneford Hospital, Oxford, UK

${ }^{2}$ University of Birmingham, UK

\section{Corresponding author}

Paul E. Jenkins, D.Clin.Psychol.

Cotswold House Eating Disorders Service

Warneford Hospital

Oxford OX3 7JX

United Kingdom

Tel: +44(0)1865902315

Fax: +44 (0)1865 337417

E-mail:pej106@gmail.com 
One-day carers workshop

\begin{abstract}
Carers of individuals with eating disorders (EDs) report high levels of burden and distress and describe a number of unmet needs. As a result, a number of interventions have been designed to support carers, including the 'Maudsley eating disorder collaborative care skills workshops', which comprise six two-hour workshops delivered over three months for parents and carers of people with EDs. The current study aimed to test a proof-of-concept that this workshop could be effectively delivered in one day. An additional aim was to assess whether the workshop had direct effects on carer skills. A non-experimental repeated measures research design was employed, giving measures before and after a one-day workshop. Results suggested significant increases in carer self-efficacy and carer skills, with moderate to large effect sizes. Qualitative analyses supported these results whilst also generating ideas to improve the one-day workshop.
\end{abstract}

Key practitioner message:

- Maudsley eating disorder collaborative care skills workshops can be delivered in one day

- Effect sizes are similar to those of existing studies

- Workshop resulted in improvements in carer self-efficacy and carer skills although longterm outcomes are unknown

Keywords: eating disorder; carers; workshop; family intervention 
$\underline{\text { Introduction }}$

Carers of individuals with eating disorders (EDs) have been found to suffer significant psychological distress, with elevated levels of mental health difficulties and burden due to their role as caregivers (e.g., Whitney, Haigh, Weinman, \& Treasure, 2007; see also Anastasiadou, Medina-Pradas, Sepulveda, \& Treasure, 2014). Living with an individual with an ED has been shown to have a number of deleterious effects on family functioning, although most studies of interventions designed to address the issues carers face have been conducted on mothers of patients with anorexia nervosa (AN) (Anastasiadou et al., 2014). Caring for a loved one with AN is likely to be particularly demanding in light of the significant duration of the illness, elevated mortality rate, and high levels of comorbidity (e.g., see Eckert, Halmi, Marchi, Grove, \& Crosby, 1995; Arcelus, Mitchell, Wales, \& Nielsen, 2011).

Given the documented impact on carer burden and distress, a number of interventions (see Hibbs et al., 2015b, for a review) have been designed to help carers to provide support and view families as 'the solution and not the problem' (Treasure \& Nazar, 2016). In other mental health conditions, such interventions have been found to improve the experience of caregiving, as well as quality of life and reduction in psychological distress (see YesufuUdechuku et al., 2015). Although such interventions are typically delivered in person, often in group format, a range of methods of delivery (such as shorter interventions, online delivery, and bibliotherapy) is likely to reflect the broad needs of carers (e.g., Harding \& Higginson, 2003; see also Haigh \& Treasure, 2003).

'The Maudsley eating disorder collaborative care skills workshops' or the 'New Maudsley Method' has been designed as a carer-focused intervention for families affected by the range of EDs, not just AN (Treasure, Smith, \& Crane, 2007; Sepulveda, Lopez, Todd, Whitaker, \& 
Treasure, 2008), although some qualitative feedback has reported that workshops can be too “AN focussed" (Linacre, Green \& Sharma, 2016, p. 302). The workshops are based on psychological theories of caregiver coping which highlight issues such as denial of symptoms, the stigma of EDs, and the importance of behaviours that can reinforce symptoms of an ED (see Treasure, Whitaker, Whitney, \& Schmidt, 2005). The model aims to “interrupt" maintaining mechanisms in eating pathology (Treasure et al., 2007, p. 26) and is strongly based on the model of AN maintenance proposed by Schmidt and Treasure (2006). This model emphasises the role of perfectionism and cognitive rigidity, experiential avoidance, 'pro-anorexic' beliefs, and the behaviour of close others in maintaining EDs. The workshops, therefore, target issues related to these maintenance factors such as understanding the nature of EDs, effective communication strategies, problem-solving, and reflecting on an individual's readiness to make changes (see Table 1). The workshops are strongly based on the principles of Motivational Interviewing (e.g., see Rollnick \& Miller, 1995), which are taught to carers as part of the workshops. For example, skills such as asking Open questions, Affirmation, Reflection, and Summarising (OARS) are key elements and have been reported to have particular value in qualitative evaluations of this approach (e.g., Linacre et al., 2016). Motivational interviewing has been found to be particularly helpful for people who are ambivalent about change (Treasure, 2004; Miller \& Rollnick, 2002) and has also been an effective approach when working with carers (e.g., Macdonald, Hibbs, Corfield, \& Treasure, 2011).

Evaluating the feasibility of such an intervention, Sepulveda et al. (2008) reported on data from 35 carers receiving six two-hour workshops over three months, extended by a later study (Sepulveda et al., 2010). Feedback from attendees was generally positive and selfreport measures suggested significant reductions in levels of carer distress, expressed 
One-day carers workshop

emotion, and burden. The results suggest that mechanisms hypothesised to maintain ED pathology (e.g., Schmidt \& Treasure, 2006) can be usefully addressed by this approach.

The model has been exported to other countries, such as Australia (Pépin \& King, 2016) and Spain (Gutiérrez Álvarez, Sepúlveda, Anastasiadou, \& Parks, 2013), supporting and extending the results of the original UK studies. All have used the format of six groups delivered over a number of weeks and reported high rates of attendance, although a recent pilot study by Linacre et al. (2016) trialled an intervention that modified the core elements of the Maudsley workshop, delivered over seven sessions. This small study concluded that some adaptations could be made to the New Maudsley Method and the intervention was associated with improvements in carer experiences of stigma, dependency, and loss (using a measure of carer experience; Szmukler et al., 1996) as well as improved perceptions of a positive relationship with the sufferer.

In summary, results have shown moderate effect sizes on variables such as carer distress and burden, and a reduction of behaviours that are thought to maintain EDs (Hibbs et al., 2015b). However, only recently has a measure been developed that directly addresses carer skills (Hibbs et al., 2015a), and therefore this has not been extensively evaluated in existing intervention studies (Linacre et al., 2016).

In addition to limited data on whether caregiver skills are directly affected by the Maudsley eating disorder collaborative care skills workshops, it is also not known whether similar results can be obtained from an intervention which covers the topics in one day. Possible advantages to this include flexibility in how training is delivered, greater availability to a wider range of carers who may be unable to commit to regular weekly sessions, and less professional time needed. A one-day group may miss some of elements of the original workshops, such as writing and practising skills between sessions, but it is possible that key 
One-day carers workshop

features can be covered in sufficient detail to help carers develop the skills needed to help the sufferer with an ED recover from their illness (see Treasure et al., 2007). Another possible disadvantage is that chances to develop supportive relationships with other carers may be more limited in a one-day workshop, particularly important given that social isolation is often a common part of carer experience, is related to levels of distress, and can be improved through carer interventions (e.g., Linacre et al., 2016; Sepulveda et al., 2008). The aims of this study were to assess the feasibility of an intervention based on the original workshops but run over one day and explore whether there are similar effects on caregiving skills and parental self-efficacy. As an additional aim, we were interested in whether there were differences between carers of children ( $<18$ years) and adults. 


\section{Materials and Methods}

\section{Description of Intervention}

The workshop (facilitated by JH, JC, SP, and AS) was intended to improve carer self-efficacy and confidence in managing the burden often felt by loved ones of those living with EDs. It is based on the Maudsley eating disorder collaborative care skills workshops and 'SkillsBased Learning for Caring for a Loved One with an Eating Disorder: The New Maudsley Method', developed by Janet Treasure and others at the Maudsley Hospital (Treasure, Smith, $\&$ Crane, 2007). It is a one-day interactive workshop lasting approximately seven hours that is separated into four sections: (1) the biopsychosocial model of EDs, including information on how EDs develop and are maintained; (2) carer styles, including discussion of different responses that carers may show towards their family member with an ED; (3) cycles of motivation and how to interact motivationally and foster change; and (4) caring for oneself as a carer (see Table 1). During the day there is formal teaching, small group work, experiential learning, discussion and reflection. Condensing the workshop resulted in less time for discussion, role plays and group exercises, although key topics were covered (see Table 1). Video clips were also omitted. Professionals working with people with EDs are encouraged to attend alongside parents, partners, siblings and other carers in order to encourage discussion and learning between carers and professionals.

\section{Procedure}

The study used a non-experimental design to look at data collected from a series of workshops for carers. As part of routine service evaluation, all carers attending the groups were given the measures described below. They were asked to complete these on arrival at the workshop and again shortly before its end. Carers were also asked to complete a 
One-day carers workshop

demographics questionnaire that included information (e.g., age, employment status) about themselves and the individual with an ED for whom they cared.

\section{Sample size}

An a priori power analysis was based on existing pilot work (e.g., Pépin \& King, 2016; Sepulveda et al., 2008) finding moderate effect sizes (Cohen's $d \approx 0.5$ ) on measures of carer experience. Given assumed Type 1 and 2 error rates of $5 \%(\alpha / \beta=0.95)$, this suggests that a sample size of at least 45 is needed (Faul, Erdfelder, Lang, \& Buchner, 2007).

\section{Participants}

Participants were invited because they were carers of a patient with an ED, open to local mental health services. In total, four groups were run during the period between May 2015 and May 2016 with 95 attendees (mean attendance $=23.8$, range $=21-26$ ). Although this was considered a service evaluation, seven individuals explicitly stated that they did not want their data used for research purposes and were excluded from the current analysis. Therefore, data from 88 individuals is presented. Data were collected as part of routine care and the local NHS Trust Research and Development department granted permission for the study, noting that further NHS Research Ethics Committee approval was not required.

The group was run for carers of both adults and young people with EDs, with an additional goal of increasing understanding of care provision in order to improve the experience of transition from children to adult services that also reflected previous work in this area (e.g., Pépin \& King, 2016; Sepulveda et al., 2008).

The sample consisted of 77 parents (23 fathers, 53 mothers, $1=$ missing), four siblings ( 1 male, 3 female), three spouses (all male), one grandmother, and one step-father. Data regarding the relationship with two other individuals was missing. Of the sample, 73 (83\%) 
One-day carers workshop

were living with the individual with an ED at the time of the workshop they attended and reported an average of 9.2 hours per day spent with the person. Most carers were working and had other children. Ages of carers ranged from 21 to 71 years (missing from one individual), with a mean (SD) of 49.9 (8.7) years. Carers were also asked to provide information on the individuals with an ED for whom they cared. Ages ranged from 10 to 46 years $($ mean $=19.6, \mathrm{SD}=6.3)$ and, of 86 on whom information was provided, $79(91.9 \%)$ were female. At the time of the workshop, 32/82 (39.0\%) had been admitted to psychiatric hospital at least once. Duration of illness (as reported by carers) ranged from $<1$ year to 32 years with a mean of 2.6 years $(\mathrm{SD}=4.80)$. Information on diagnoses was not available.

\section{Measures}

\section{Parental self-efficacy}

Parental self-efficacy was assessed with a revised version of the Parents Versus Anorexia Scale (PVA; Rhodes, Baillie, Brown, \& Madden, 2005; see Lafrance Robinson, Dolhanty, Stillar, Henderson, \& Mayman, 2014, for details of the revision). This 7-item measure is rated on a 5-point scale from 1 ('Strongly disagree') to 5 ('Strongly agree') and therefore total scores range from 7 - 35, with higher scores indicating greater parental self-efficacy. An example item is 'I feel equipped with specific practical strategies for the task of bringing about the complete recovery of my child in the home setting'. The PVA has shown to be sensitive to change following interventions for parents and carers (e.g., Lafrance Robinson et al., 2014; Spettigue et al., 2015). Cronbach's $\alpha$ are shown in Table 2.

\section{Carer skills}

Carer skills were assessed with the CASK (Hibbs et al., 2015a), a 27-item measure comprising six factors assessing different aspects of carer skills in supporting individuals 
One-day carers workshop

with EDs: Bigger Picture; Self-Care; Biting-Your-Tongue; Insight and Acceptance;

Emotional Intelligence; and Frustration Tolerance. An example item is 'How confident are you that you can... be calm when dealing with difficult behaviours associated with the eating disorder?'. Responses are given on an 11-point scale of percentages from $0 \%$ ('Almost never') $-100 \%$ ('Almost always'), where "a rating of 100 means that you are absolutely, $100 \%$ confident that you could perform the activity whenever you wished". It has previously been used in a one-day carers workshop and shows good initial psychometric properties (Hibbs et al., 2015a). Cronbach's $\alpha$ in the current sample are shown in Table 2.

\section{Acceptability}

A number of short questions assessed how helpful, useful, and interesting the attendees found the workshop, rated on a $0-10$ scale (e.g., from Not Helpful to Very Helpful). Space was also left for comments to be made.

\section{Data Analysis}

Repeated measures $t$-tests were used to compare scores before and after the intervention, although not all participants completed all measures. Results are presented as intent-to-treat. As the number of individuals missing post-intervention data was relatively small $(n=16$; $18.2 \%$ ) and the study was primarily a proof-of-concept design, the baseline observation carried forward (BOCF) approach was taken to estimate intervention effects (see also Pépin \& King, 2016). One participant was missing both post-treatment and pre-treatment data for the CASK so BOCF was not possible.

Qualitative feedback was given in response to an evaluation question after the workshop had been delivered: 'Are there any other comments you wish to make?'. Responses were collated and read multiple times by one author (LP). Fourteen participants (15.9\%) provided 
One-day carers workshop

qualitative feedback, although most feedback was brief consisting of a few words (e.g., "excellent day") and therefore insufficiently detailed in order to be subjected to formal thematic analysis (e.g., Braun \& Clarke, 2006). However, themes reflecting the experience of the workshop were identified using line-by-line coding, and later clustered into appropriate overarching themes that occurred in numerous responses. Extracted themes were then reviewed by SB, a clinical psychologist, who had no role in facilitating the groups. SB reread the qualitative feedback comments to check whether the extracted themes identified by LP fit with the raw data, were accurate representations of the raw data, and to help determine that they were, indeed, themes (Braun \& Clarke, 2006).

\section{$\underline{\text { Results }}$}

Post-intervention scores on the PVA and CASK were significantly higher than preintervention scores (see Table 2). Effect sizes (Hedge's $g$ ) ranged from 0.46 to 0.86 , suggesting at least moderate-sized effects of the one-day workshop on carer self-efficacy and skills.

\section{[INSERT TABLE 2]}

Participants appeared generally satisfied with the intervention, with 55 of 69 who responded (79.7\%) rating the workshop as at least 8/10 in terms of helpfulness. Similarly, 48 of 67 (71.6\%) rated it as at least $8 / 10$ for usefulness and $84.7 \%(61 / 72)$ scored the workshop as at least $8 / 10$ for level of interest.

Feedback about the programme

Four themes were extracted from the data (see also Figure 1): 
One-day carers workshop

1. Growth of knowledge, skills, and understanding. Participants commented on how the workshop broadened their knowledge and understanding of EDs; in particular, building their skills and confidence in managing and supporting an individual with an ED. Participants reported that the workshop enhanced their communication skills, referencing group tasks (e.g., role play).

"I feel I now understand ED a bit better knowing how to communicate. Role play excellent, reinforced my action. A lot of useful information." (Participant 33)

"Very good strategies for coping and different ways to react, care, cope." (Participant 26)

2. Emotional. Some participants found the workshop anxiety-provoking, with one individual noting that it was "quite terrifying” (Participant number 21). Conversely, some noted it to be a positive experience with feedback such as "excellent" (Participant 11) and "brilliant" (Participant 10).

3. Togetherness. Participants commented on the therapeutic value of meeting other carers at the workshop. Specifically, carers felt they were less alone, enjoyed sharing their own experiences with other carers, and found it useful to exchange strategies for managing difficult behaviours.

"Sharing experiences has made me feel there are others who understand" (Participant 21)

\section{"I don't feel so alone" (Participant 19)}

However, one participant found it disadvantageous to meet other carers, and found it detracted from the message of the workshop: 
One-day carers workshop

"People [are] always tempted (including myself) to bring everything back to personal experience. While useful this sometimes undermined the point of the exercise." (Participant 13)

4. Logistics feedback. Some participants commented on the logistics of coordinating an allday workshop, such as feeling that the day was "quite long" (Participant 62) and that it “could be more focussed" (Participant 67).

Carers of children and those of adults

Responses from carers of individuals under $18(\mathrm{n}=34,38.6 \%)$ were compared with those who cared for adults $(n=54,61.4 \%)$, shown in Table 3 .

\section{[INSERT TABLE 3]}

The only difference observed between these two groups was on the PVA, with carers of adults reporting lower scores at both pre- and post-intervention. The effects of the intervention remained significant in both groups, although the magnitude of change (effect sizes) was slightly lower for the PVA in carers of adults. 


\section{$\underline{\text { Discussion }}$}

The results of this study suggest that a skills-based workshop for carers (based on the Maudsley eating disorder collaborative care skills workshops) can be effective when delivered in one day. Furthermore, most carers of patients with EDs reported the intervention to be helpful, interesting, and useful and also provided qualitative feedback that supported quantitative data. As expected, improvements were seen across the group on a measure of self-efficacy, suggesting that carers felt greater confidence in their role in their loved one's recovery following the workshop. Although we did not look in more detail at specific elements of the workshop, qualitative comments suggest that the emphasis on psychoeducation, active exercises with role play, and trying out new skills helped increase confidence as did the discussion and sharing of ideas with other carers. It is also possible that informal discussions throughout the day between attendees contributed to the increase in confidence of carers, and further studies might use more in-depth qualitative methodology to explore similar themes and mechanisms of change.

The study used a relatively new measure to directly assess carers' confidence in their skills to manage aspects of an ED (the CASK; Hibbs et al., 2015a). Results showed significant improvements on all aspects of carer skills, further supporting the utility of this workshop in addressing possible maintaining mechanisms in EDs. Hibbs et al. (2015a) reported using the CASK to assess change following a number of interventions, with an overall effect size of all interventions for the Total CASK score to be 0.59 (reported as Cohen's $d$ ). Such similarity with the results presented here is encouraging, although further studies, including those with follow-up data, will be required to directly assess the relative efficacy of the New Maudsley Method delivered in different formats. 
The intervention was provided to a wide range of carers, under an overarching goal of reducing discontinuity in care provision between children and adults with psychiatric problems (e.g., see Singh, Evans, Sireling, \& Stuart, 2005). Results of analyses looking at carers of adults and carers of children were, perhaps surprisingly, similar. For example, carers spent a similar amount of time looking after the individual with an ED and also scored similarly on a measure of carer skills (both before and after the intervention). However, significant differences were seen on a measure of self-efficacy, the PVA (Rhodes et al., 2005). This suggests that carers of older individuals might feel less confident in managing eating pathology, despite having a similar level of skills. Differences could be due to the discrepant rights and responsibilities afforded carers of younger individuals, or that the illness may have taken a more "protracted course" in adults (Treasure et al., 2005, p. 159). Few studies have looked at these factors in detail although the impact of carer interventions may be related to the duration of the illness and level of care required (Linacre et al., 2016; see also Treasure, Stein, \& Maguire, 2015), which might be an interesting avenue for further research. A large effect was seen on parental self-efficacy in a study evaluating a 2-day intervention for carers based on emotion-focused therapy (Lafrance Robinson et al., 2014), with mean PVA scores increasing from 18.56 to 26.06. These scores are similar to those obtained with the younger subsample in the current study, albeit with a larger magnitude of effect. This could reflect the tendency for carers of sufferers under the age of 18 to take a more active role in encouraging change, resulting in increased confidence as they learn to do this, and is important given findings that parental self-efficacy predicts outcomes in familybased therapy for EDs (e.g., Lafrance Robinson, Strahan, Girz, Wilson, \& Boachie, 2013).

Characteristics of the sample were similar to other studies (e.g., Pépin \& King, 2016) in terms of the ages of both carers who attended and the individuals being cared for. For example, around $80 \%$ in both the current study and that of Pépin and King (2016) were living with the 
person with an ED (a similar proportion of $75 \%$ was reported in Sepulveda et al., 2008).

However, average time spent with their loved one was reported by carers in the current study to be around 9 hours a day, compared to 6.4 hours in Pépin and King and the number of patients with more than one previous admission was higher in the Australian group (66\% of the sample versus $39 \%$ in the current study). Duration of illness was reported to be longer in the current sample (3.5 years) compared to the Australian group (1.9 years). It is not yet clear how differences might affect outcome, and to what extent workshops should be modified to suit attendees' needs (Linacre et al., 2016); further work might seek to consider this. For example, both the current workshop and that of Pépin and King provided support for carers of adults and children with eating problems; although this was felt to be an advantage, it may neglect the needs of different sub-populations, such as the very young or those with a severe and enduring illness.

Although only a subset of participants provided feedback, a number of themes emerged from qualitative analyses. Participants were generally satisfied with the workshop, feeling that it improved their communication skills and understanding of EDs, and also developed a sense of togetherness. Carers acknowledged experiencing a range of emotions and that a one-day workshop can feel long and emotionally demanding, although the majority of responses indicated that overall the workshop had been perceived as useful. Based on this, potential suggestions to improve the workshop might include modifying the structure of the workshop to allow for greater support to those experiencing higher anxiety. Provision of more information before the workshop and creating a workbook to use alongside (containing material related to presentations and skills that participants are able to take away and review if necessary) may also be of benefit. There may be individuals who prefer a one-day workshop and others for whom a series of workshops over a longer timeframe may be a better alternative; the results presented here suggest that both can be effective, and future 
One-day carers workshop

studies might also consider the longer-term impact of the intervention, perhaps through studies with a follow-up period.

This was one of the largest studies of caregiver interventions in EDs (see Hibbs et al., 2015b, for a review) although was limited by lack of a control group and follow-up, allocation to a comparison condition (e.g., a longer group), and a wider complement of measures, such as those assessing carer distress, expressed emotion, and accommodating and enabling behaviour (e.g., see Sepulveda, Kyriacou, \& Treasure, 2009). It was possible that respondents not providing data did not benefit, or were disadvantaged, following the intervention. Rather than omitting data, we used the BOCF method for handling missing data, which assumes no change following an intervention; however, drawbacks with this have been reported and further studies in this area might consider a more sophisticated method for handling missing data, such as multiple imputation or maximum likelihood approaches (e.g., see O'Kelly \& Ratitch, 2014). Although feedback was insufficiently detailed for formal qualitative analysis, a number of themes emerged and supported quantitative data on the effectiveness of the intervention. The study used a relatively new measure which aims to assess the "key skills taught in caregiver interventions" (Hibbs et al., 2015a, p. 291) and provides preliminary evidence for its utility. The study assessed the effectiveness of a structured intervention, based on an established model, over four separate groups. Carers of both adults and sufferers under the age of 18 attended the workshop, which was reduced from twelve hours (six two-hour sessions) to seven hours and may therefore require less facilitator time to deliver. Moreover a one day workshop could potentially be attractive to a subset of carers who would find it difficult to attend the course over six evenings. Future studies might consider the optimal length of the Maudsley eating disorder collaborative care skills workshops, and might also seek to determine whether these effects on carer skills transfer to improvements in eating pathology. Interesting data is presented by Magill et al. (2015) who 
One-day carers workshop

found that an intervention for carers based on carer education and skills, provided in written and electronic form (ECHO; see Rhind et al., 2014), suggested improvement in patient outcomes compared to treatment-as-usual, although many differences were not statistically significant. It would be interesting to see whether effects of the Maudsley workshops enhance patient outcomes in similar ways.

Despite limitations, the current study provides early evidence that the Maudsley eating disorder collaborative care skills workshops can be delivered flexibly - a shorter workshop of one day has been shown to have similar outcomes to a longer version. The promising findings presented here suggest that a one-day workshop can enhance carer self-efficacy and increase their skills in supporting individuals with EDs, although longer-term outcomes are not yet known. 


\section{Acknowledgements}

We would like to thank Professor Janet Treasure and Gill Todd, and their team at South London and Maudsley NHS Foundation Trust. Jo Holliday supported the initial development of the workshop and we would also like to thank Jessica Staniford who helped collate information for the study. Finally, we would like to thank all professionals who have attended and supported the workshops, and all carers who have attended; without them the workshop would not have taken place and developed over the years. 


\section{References}

Anastasiadou, D., Medina-Pradas, C., Sepulveda, A. R., \& Treasure, J. (2014). A systematic review of family caregiving in eating disorders. Eating Behaviors, 15, 464-477. doi: 10.1016/j.eatbeh.2014.06.001

Arcelus, J., Mitchell, A. J., Wales, J., \& Nielsen, S. (2011). Mortality rates in patients with anorexia nervosa and other eating disorders: a meta-analysis of 36 studies. Archives of General Psychiatry, 68, 724-731. doi:10.1001/archgenpsychiatry.2011.74

Braun, V., \& Clarke, V. (2006). Using thematic analysis in psychology. Qualitative Research in Psychology, 3, 77-101.

Eckert, E. D., Halmi, K. A., Marchi, P., Grove, W., \& Crosby, R. (1995). Ten-year follow-up of anorexia nervosa: clinical course and outcome. Psychological Medicine, 25, 143-156.

Faul, F., Erdfelder, E., Lang, A.-G., \& Buchner, A. (2007). G*Power 3: a flexible statistical power analysis program for the social, behavioral, and biomedical sciences. Behavior Research Methods, 39, 175-191. doi: 10.3758/BF03193146

Gutiérrez Álvarez, E., Sepúlveda, A. R., Anastasiadou, D., \& Parks, M. (2013). Family and eating disorders: advances in evaluation, design and psychoeducational intervention. Clínica Contemporánea, 4, 107-117.

Haigh, R., \& Treasure, J. (2003). Investigating the needs of carers in the area of eating disorders: development of the Carers' Needs Assessment Measure (CaNAM). European Eating Disorders Review, 11, 125-141. doi: 10.1002/erv.487 
Harding, R., \& Higginson, I. J. (2003). What is the best way to help caregivers in cancer and palliative care? A systematic literature review of interventions and their effectiveness. Palliative Medicine, 17, 63-74.

Hibbs, R., Rhind, C., Salerno, L., Lo Coco, G., Goddard, E., Schmidt, U., Micali, N., Gowers, S., Beecham, J., Macdonald, P., Todd, G., Campbell, I., \& Treasure, J. (2015a). Development and validation of a scale to measure caregiver skills in eating disorders. International Journal of Eating Disorders, 48, 290-297. doi: 10.1002/eat.22362

Hibbs, R., Rhind, C., Leppanen, J., \& Treasure, J. (2015b). Interventions for caregivers of someone with an eating disorder: a meta-analysis. International Journal of Eating Disorders, 48, 349-361. doi: 10.1002/eat.22298

Lafrance Robinson A., Strahan, E., Girz, L., Wilson, A., \& Boachie, A. (2013). 'I know I can help you': parental self-efficacy predicts adolescent outcomes in family-based therapy for eating disorders. European Eating Disorders Review, 21, 108 - 114. doi: 10.1002/erv.2180

Lafrance Robinson, A., Dolhanty, J., Stillar, A., Henderson, K., \& Mayman, S. (2014). Emotion-focused family therapy for eating disorders across the lifespan: A pilot study of a 2day transdiagnostic intervention for parents. Clinical Psychology \& Psychotherapy, 23, 1423. doi: $10.1002 /$ cpp.1933

Linacre, S., Green, J., \& Sharma, V. (2016). A pilot study with adaptations to the Maudsley Method approach on workshops for carers of people with eating disorders. Mental Health Review Journal, 21, 295-307.

Macdonald, P., Hibbs, R., Corfield, F., Treasure, J. (2011). The use of motivational interviewing in eating disorders: a systematic review. Psychiatry Research, 200,1-11. doi: 10.1016/j.psychres.2012.05.013 
Magill, N., Rhind, C., Hibbs, R., Goddard, E., Macdonald, P., Arcelus, J., Morgan, J., Beecham, J., Schmidt, U., Landau, S., \& Treasure, J. (2015). Two-year follow-up of a pragmatic randomised controlled trial examining the effect of adding a carer's skill training intervention in inpatients with anorexia nervosa. European Eating Disorders Review, 24, 122-130. doi: 10.1002/erv.2422

Miller, W. R., Rollnick, S. (2002). Motivational interviewing: preparing people to change. New York, NY: Guilford Press.

O'Kelly, M., \& Ratitch, B. (2014). Clinical trials with missing data: a guide for practitioners. Chichester, West Sussex: Wiley.

Pépin, G., \& King, R. (2016). Collaborative care skill training workshop: how Australian carers support a loved one with an eating disorder. Advances in Eating Disorders: Theory, Research and Practice, 4, 47-58. doi: 10.1080/21662630.2015.1081823

Rhind, C., Hibbs, R., Goddard, E., Schmidt, U., Micali, N., Gowers, S., Beecham, J., Macdonald, P., Todd, G., Tchanturia, K., \& Treasure, J. (2014). Experienced Carers Helping Others (ECHO): Protocol for a pilot randomised controlled trial to examine a psychoeducational intervention for adolescents with anorexia nervosa and their carers. European Eating Disorders Review, 22, 267-277. doi: 10.1002/erv.2298

Rhodes, P., Baillie, A., Brown, J., \& Madden, S. (2005). Parental efficacy in the familybased treatment of anorexia: preliminary development of the Parents Versus Anorexia Scale (PVA). European Eating Disorders Review 13, 399-405. doi: 10.1002/erv.661

Rollnick, S., \& Miller, W. R. (1995). What is Motivational Interviewing? Behavioural and Cognitive Psychotherapy, 23, 325-334. 
One-day carers workshop

Schmidt, U., \& Treasure, J. (2006). Anorexia nervosa: Valued and visible. A cognitiveinterpersonal maintenance model and its implications for research and practice. British Journal of Clinical Psychology, 45, 343-366. doi: 10.1348/014466505X53092

Sepulveda, A. R., Kyriacou, O., \& Treasure, J. (2009). Development and validation of the Accommodation and Enabling Scale for Eating Disorders (AESED) for caregivers in eating disorders. BMC Health Services Research, 9, 171. doi: 10.1186/1472-6963-9-171

Sepulveda, A. R., Lopez, C., Todd, G., Whitaker, W., \& Treasure, J. (2008). An examination of the impact of "the Maudsley eating disorder collaborative care skills workshops" on the well being of carers: a pilot study. Social Psychiatry and Psychiatric Epidemiology, 43, 584591. doi: 10.1007/s00127-008-0336-y

Sepulveda, A. R., Todd, G., Whitaker, W., Grover, M., Stahl, D., \& Treasure, J. (2010). Expressed emotion in relatives of patients with eating disorders following skills training program. International Journal of Eating Disorders, 43, 603-610. doi: 10.1002/eat.20749

Singh, S. P., Evans, N., Sireling, L., \& Stuart, H. (2005). Mind the gap: the interface between child and adult mental health services. Psychiatric Bulletin, 29, 292-295. doi: 10.1192/bjp.187.5.398

Spettigue, W., Maras, D., Obeid, N., Henderson, K. A., Buchholz, A., Gomez, R., \& Norris, M. L. (2015). A psycho-education intervention for parents of adolescents with eating disorders: a randomized controlled trial. Eating Disorders, 23, 60-75. doi: $10.1080 / 10640266.2014 .940790$

Szmukler, G. I., Burgess, P., Herrman, H., Bloch, S., Benson, A., \& Colusa, S. (1996). Caring for relatives with serious mental illness: The development of the Experience of Caregiving Inventory. Social Psychiatry and Psychiatric Epidemiology, 31, 137-148. 
One-day carers workshop

Treasure, J. (2004). Motivational interviewing. Advances in Psychiatric Treatment, 10, 331337. doi: 10.1192/apt.10.5.331

Treasure, J., \& Nazar, B. P. (2016). Interventions for the carers of patients with eating disorders. Current Psychiatry Reports, 18, 16. doi: 10.1007/s11920-015-0652-3.

Treasure, J., Sepulveda, A. R., Whitaker, W., Todd, G., Lopez, C., \& Whitney, J. (2007). Collaborative care between professionals and non-professionals in the management of eating disorders: a description of workshops focussed on interpersonal maintaining factors. European Eating Disorders Review 15, 24-34. doi: 10.1002/erv.758

Treasure, J., Smith, G., \& Crane, A. (2007). Skills-based learning for caring for a loved one with an eating disorder. Hove, East Sussex: Routledge.

Treasure, J., Stein, D., \& Maguire, S. (2015). Has the time come for a staging model to map the course of eating disorders from high risk to severe enduring illness? An examination of the evidence. Early Intervention in Psychiatry, 9, 173-184. doi: 10.1111/eip.12170

Treasure, J., Whitaker, W., Whitney, J., \& Schmidt, U. (2005). Working with families of adults with anorexia nervosa. Journal of Family Therapy, 27, 158-170. doi: 10.1111/j.14676427.2005.00308.x

Yesufu-Udechuku, A., Harrison, B., Mayo-Wilson, E., Young, N., Woodhams, P., Shiers, D., Kuipers, E., \& Kendall, T. (2015). Interventions to improve the experience of caring for people with severe mental illness: Systematic review and meta-analysis. The British Journal of Psychiatry, 206, 268-274.

Whitney, J., Haigh, R., Weinman, J., \& Treasure, J. (2007). Caring for people with eating disorders: factors associated with psychological distress and negative caregiving appraisals in 
carers of people with eating disorders. British Journal of Clinical Psychology, 46, 413-428. doi: $10.1348 / 014466507 X 173781$ 
Table 1. Content of the workshop.

\begin{tabular}{|c|c|c|c|c|}
\hline & Title & What is covered & Methods used & Aims \\
\hline Introduction & Introduction & $\begin{array}{l}\text { 'Ground rules' } \\
\text { Introduction to } \\
\text { collaborative model } \\
\text { of caring }\end{array}$ & Presentation & $\begin{array}{l}\text { Introduce the } \\
\text { content of the } \\
\text { day and } \\
\text { workshop }\end{array}$ \\
\hline Session 1 & $\begin{array}{l}\text { Understanding } \\
\text { EDs }\end{array}$ & $\begin{array}{l}\text { Psycho-education } \\
\text { regarding the } \\
\text { development, } \\
\text { maintenance, and } \\
\text { consequences of EDs } \\
\text { and the impact on } \\
\text { carers }\end{array}$ & $\begin{array}{l}\text { Presentation } \\
\text { Group } \\
\text { discussion }\end{array}$ & $\begin{array}{l}\text { Increase } \\
\text { understanding of } \\
\text { EDs and their } \\
\text { consequences, in } \\
\text { order to respond } \\
\text { helpfully }\end{array}$ \\
\hline Session 2 & Styles of caring & $\begin{array}{l}\text { Theory of expressed } \\
\text { emotion } \\
\text { Carer styles of } \\
\text { responding using } \\
\text { animal metaphors } \\
\text { Carer styles and } \\
\text { skills training in } \\
\text { relation to meal } \\
\text { planning and } \\
\text { supported eating }\end{array}$ & $\begin{array}{l}\text { Small group } \\
\text { discussion of } \\
\text { carer styles } \\
\text { Plenary } \\
\text { feedback and } \\
\text { discussion of } \\
\text { helpful styles }\end{array}$ & $\begin{array}{l}\text { Address key } \\
\text { maintenance } \\
\text { factors of EDs - } \\
\text { the response of } \\
\text { close others }\end{array}$ \\
\hline Session 3 & $\begin{array}{l}\text { Motivating } \\
\text { towards } \\
\text { recovery }\end{array}$ & $\begin{array}{l}\text { Stages of change and } \\
\text { motivational } \\
\text { interviewing } \\
\text { principles } \\
\text { Decisional balance } \\
\text { Self-motivational } \\
\text { statements and } \\
\text { change talk } \\
\text { Affirmations, } \\
\text { reflective listening, } \\
\text { and other 'micro- } \\
\text { skills' (e.g., OARS) }\end{array}$ & $\begin{array}{l}\text { Presentation of } \\
\text { ideas to the } \\
\text { group } \\
\text { Group exercises } \\
\text { Role play }\end{array}$ & $\begin{array}{l}\text { Enable carers to } \\
\text { understand the } \\
\text { cycle of change } \\
\text { and to respond } \\
\text { motivationally } \\
\text { to the sufferer, } \\
\text { encouraging } \\
\text { change. }\end{array}$ \\
\hline Session 4 & $\begin{array}{l}\text { Caring for } \\
\text { carers }\end{array}$ & $\begin{array}{l}\text { Coping with the } \\
\text { caring role } \\
\text { Role of siblings and } \\
\text { their needs } \\
\text { Tackling adversity } \\
\text { Looking after oneself } \\
\text { Modelling change }\end{array}$ & $\begin{array}{l}\text { Presentation of } \\
\text { ideas } \\
\text { Discussion of } \\
\text { scenarios } \\
\text { Small and large } \\
\text { group discussion }\end{array}$ & $\begin{array}{l}\text { Support carers } \\
\text { in developing } \\
\text { strategies to help } \\
\text { them cope in a } \\
\text { positive way and } \\
\text { model change. }\end{array}$ \\
\hline Conclusion & Conclusion & $\begin{array}{l}\text { Reflect on the day } \\
\text { and ask what carers } \\
\text { might do differently }\end{array}$ & $\begin{array}{l}\text { Presentation } \\
\text { Discussion }\end{array}$ & $\begin{array}{l}\text { Conclude } \\
\text { workshop and } \\
\text { administer } \\
\text { questionnaires }\end{array}$ \\
\hline
\end{tabular}


Table 2. Results from self-report measures before and after the intervention (intent-to-treat)

\begin{tabular}{|c|c|c|c|c|c|c|c|c|c|}
\hline \multirow{2}{*}{ Measure } & \multirow[t]{2}{*}{$\mathrm{N}$} & \multirow[t]{2}{*}{$\begin{array}{c}\text { Cronbachs } \\
\alpha\end{array}$} & \multicolumn{2}{|c|}{$\begin{array}{c}\text { Pre- } \\
\text { intervention }\end{array}$} & \multicolumn{2}{|c|}{$\begin{array}{c}\text { Post- } \\
\text { intervention }\end{array}$} & \multicolumn{3}{|c|}{ Test statistics } \\
\hline & & & $\mathrm{M}$ & SD & M & SD & $\mathrm{t}$ & $\mathrm{p}$ & ES \\
\hline PVA Total & 85 & 0.58 & 17.55 & 3.89 & 19.47 & 4.39 & -6.624 & $<0.001$ & 0.46 \\
\hline \multicolumn{10}{|l|}{ CASK scales } \\
\hline Bigger & 82 & 0.87 & 63.57 & 17.94 & 72.79 & 16.36 & -6.349 & $<0.001$ & 0.53 \\
\hline \multicolumn{10}{|l|}{ Picture } \\
\hline Self-Care & 83 & 0.83 & 48.13 & 18.49 & 63.97 & 17.78 & -8.969 & $<0.001$ & 0.86 \\
\hline Biting-Your- & 81 & 0.79 & 52.92 & 17.70 & 65.68 & 17.53 & -7.057 & $<0.001$ & 0.72 \\
\hline \multicolumn{10}{|l|}{ Tongue } \\
\hline Insight and & 79 & 0.69 & 58.78 & 18.06 & 72.11 & 17.58 & -7.711 & $<0.001$ & 0.74 \\
\hline \multicolumn{10}{|l|}{ Acceptance } \\
\hline Emotional & 83 & 0.77 & 58.43 & 19.31 & 68.72 & 16.52 & -5.998 & $<0.001$ & 0.56 \\
\hline \multicolumn{10}{|l|}{ Intelligence } \\
\hline Frustration & 82 & 0.87 & 62.85 & 17.48 & 72.39 & 15.74 & -6.531 & $<0.001$ & 0.56 \\
\hline Tolerance & & & & & & & & & \\
\hline
\end{tabular}

$\mathrm{ES}=$ effect size (Hedge's $g$ ); $\mathrm{M}=$ mean; PVA = Parents Versus Anorexia Scale; $\mathrm{SD}=$ standard deviation 
Table 3. Responses from carers of children and those who cared for adults, mean (SD)

\begin{tabular}{lllllll}
\hline Measure & Carers of & $\mathrm{N}$ & Carers of & $\mathrm{N}$ & $p$-value $^{1}$ & ES \\
& children & & adults & & \\
& & & & & \\
\hline Hours per day spent with & $8.10(6.0)$ & 29 & $10.02(7.55)$ & 42 & .238 & 0.27 \\
sufferer & & & & & & \\
PVA at Pre-intervention & $19.24(4.02)$ & 33 & $16.48(3.42)$ & 52 & .002 & 0.74 \\
PVA at Post-intervention & $22.06(4.21)$ & 34 & $17.72(3.74)$ & 54 & $<.001$ & 1.10 \\
CASK Total at Pre- & $57.77(14.60)$ & 32 & $60.95(13.77)$ & 51 & .327 & 0.22 \\
intervention & & & & & & \\
CASK Total at Post- & $69.15(14.15)$ & 33 & $69.77(14.12)$ & 54 & .844 & 0.04 \\
intervention & & & & & &
\end{tabular}

${ }^{1}$ Chi-square or $t$-test

$\mathrm{ES}=$ effect size $($ Hedge's $g$ ); PVA $=$ Parents Versus Anorexia Scale 
Figure 1. Thematic map of participants' responses to the question 'Are there any other comments you wish to make?'

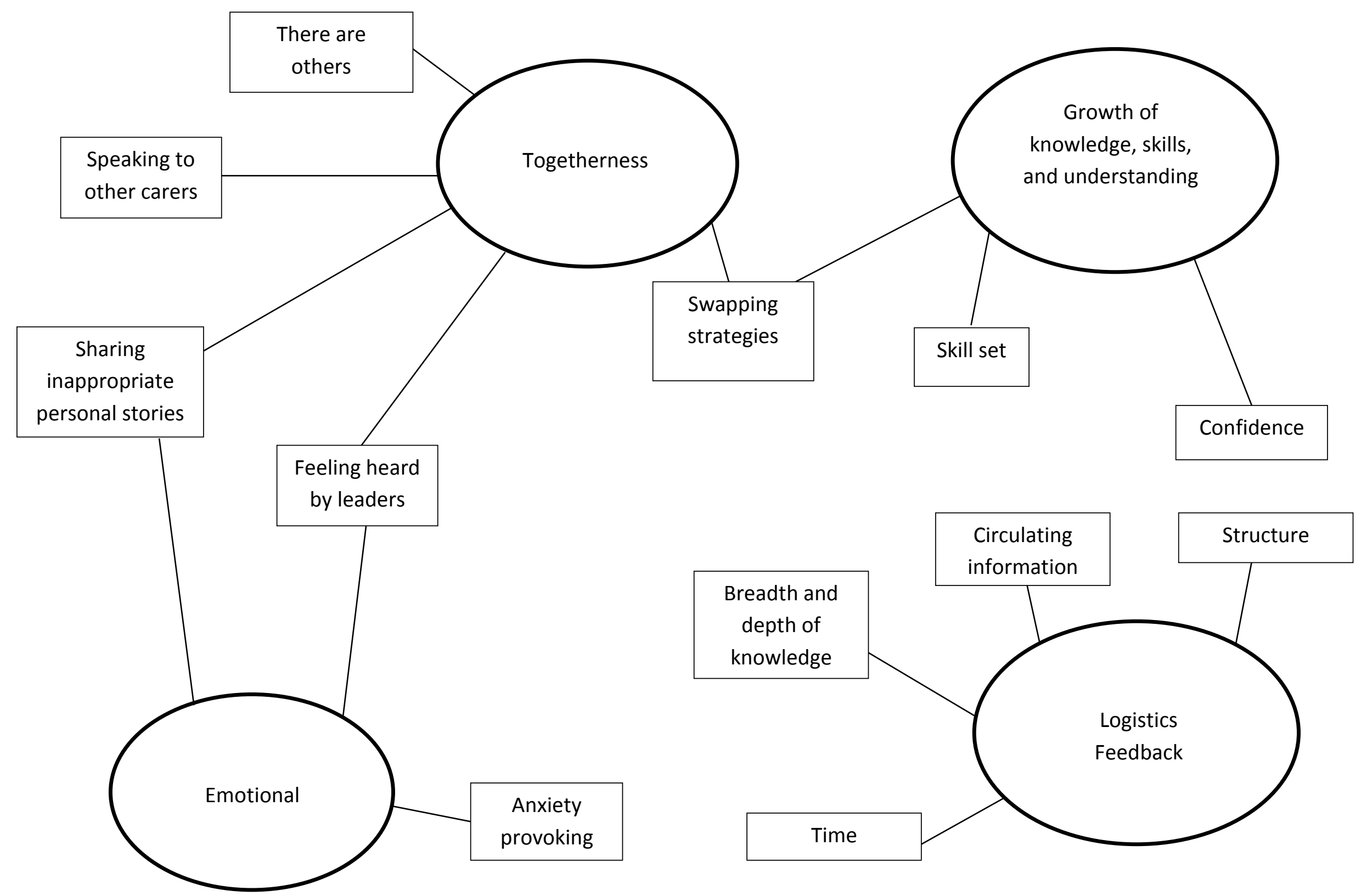

